\title{
Reductive Amination of 1-Hydroxy-2-propanone Over Nickel and Copper Catalysts
}

\author{
T. Trégner, J. Trejbal," N. Ruhswurmová, and M. Zapletal \\ Department of Organic Technology, \\ University of Chemistry and Technology Prague, \\ Technická 5, 16628 Praha 6, Czech Republic
}

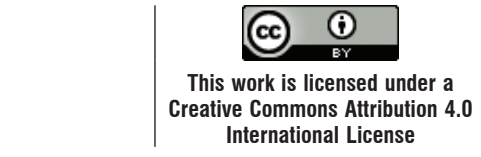

doi: 10.15255/CABEQ.2017.1077

Original scientific paper

Received: January 12, 2017

Accepted: November 7, 2017

The one-step reductive amination of 1-hydroxy-2-propanone (acetol) with ammonia to 2-aminopropanol (2-APOL) over commercial nickel and copper catalysts has been studied in the continuous fixed-bed reactor at the temperature from 130 to $220{ }^{\circ} \mathrm{C}$ and different molar ratios of reactants. It was found that the optimal molar ratios of $\mathrm{H}_{2}$ /acetol and $\mathrm{H}_{2} / \mathrm{NH}_{3}$ regarding the selectivity of 2-APOL were 25 and 1, respectively. The highest selectivity of approx. $45 \%$ to desired 2-APOL at total conversion of acetol was achieved in the presence of the nickel catalyst. Major by-products of amination were cis and trans isomers of 2,5- and 2,6-dimethylpiperazines. Mechanism of the formation of these and other detected and/or potential by-products is discussed. So far, unpublished mass spectra of identified by-products, such as $N$-substituted dimethylpiperazines or various aminoalcohols, are reported in this paper.

Keywords:

2-aminopropanol, 1-hydroxy-2-propanone, reductive amination, dimethylpiperazine

\section{Introduction}

Aliphatic amines are usually obtained by the reaction of carbonyl compounds with ammonia, primary or secondary amines in the presence of a reducing agent and a hydrogenation-dehydrogenation metal catalyst $(\mathrm{Cu}, \mathrm{Ni}, \mathrm{Co}, \mathrm{Pd}, \mathrm{Ru}, \mathrm{Rh})$. This reaction is generally known as reductive amination. From the economic point of view, the production of industrially important amino compounds usually starts from more available alcohols, the hydroxyl group of which is first converted to the more reactive carbonyl group on the surface of the metallic catalyst. Nucleophilic addition of amination agents to the carbonyl group then provides imines $(\mathrm{R}-\mathrm{N}=\mathrm{C}-\mathrm{R})$ or enamines $(\mathrm{R}-\mathrm{C}=\mathrm{C}-\mathrm{N}-\mathrm{R})$ that are subsequently easily hydrogenated to particular primary, secondary, or tertiary amines ${ }^{1-5}$.

Special group of amines is amino alcohols containing both hydroxyl and amino group in their molecule. These polyfunctional compounds combine characteristic properties of alcohols and amines and, therefore, they are important, particularly as starting substances of various chemical products (medicines, emulsifiers). The most important amino alcohols, ethanol amines and propanol amines, are produced by the reaction of ethylene oxide or propylene oxide with an amination agent. In the case of propylene oxide, isomers of 1-amino-2-propanol

${ }^{*}$ Corresponding author. Tel.: +420 22044 3689. E-mail address: jiri.trejbal@vscht.cz (J. Trejbal)
(1-APOL) are predominantly formed ${ }^{6}$. Other amino alcohols are usually produced by partial amination of particular polyols ${ }^{7,8}$ or $\alpha$-hydroxy carbonyl compounds ${ }^{9-16}$.

The reductive amination of $\alpha$-hydroxy ketones to 2-amino-1-alcohols is usually a two-stage process. First, $\alpha$-hydroxy carbonyl reacts with the amination agent to form a reaction adduct which is, in the second stage, reduced by hydrogen in the presence of the hydrogenation catalyst and amination agent to corresponding $\alpha$-amino alcohol ${ }^{9-12}$. In the case of amination of 1-hydroxy-2-propanone (acetol), isomers of 2-aminopropanols, with various substitutions on the amino group, are predominantly formed $^{13-16}$. These $\alpha$-amino alcohols can be used as solvents, emulsifiers, corrosion inhibitors, neutralizing agents in the scrubbing acidic components from natural and synthesis gases, reactive catalysts in production of polyurethane materials, intermediates in production of heterocyclic compounds (substituted piperazines), surface-active substances or medicines.

Our work has been focused on the one-step reductive amination of acetol with ammonia to 2-aminopropanol (2-APOL) over commercial nickel and copper catalysts (Scheme 1). The experiments were carried out in gaseous phase in a continuous fixedbed catalytic reactor at atmospheric pressure. The amination was conducted to total conversion of acetol. Reaction temperature was 130 or $210{ }^{\circ} \mathrm{C}$, depending on the type of catalyst $(\mathrm{Ni}$ and $\mathrm{Cu} / \mathrm{Cr}$ ). In 
addition to the catalyst, the course of amination was also monitored at various molar ratios of acetol/hydrogen/ammonia.

\section{Non-catalytic reaction of acetol with ammonia}

$\alpha$-Hydroxy ketones react easily with ammonia even at moderate reaction conditions and without catalyst to corresponding substituted 3-oxazolines or 3,4-dihydro-2H-pyrrolenine-3,4-diols ${ }^{10,17-19}$. The non-catalytic reaction of acetol with ammonia that leads to 2,4-dimethyl-2-(hydroxy methyl)-3-oxazoline is shown in Scheme $2^{19}$. The equilibrium of 3-oxazoline formation is markedly shifted towards primarily formed $\alpha$-hydroxy imine that is converted to the more stable tautomeric form of $\alpha$-amino carbonyl. The auto-condensation of the tautomer with subsequent dehydration provides 2,5-dimethyl-2,5dihydropyrazine that is stabilized by loss of hydrogen to form 2,5-dimethylpyrazine (2,5-DMPYR). At the beginning of the reaction, the major product is 3-oxazoline; its concentration decreases during the reaction at the expense of 2,5-DMPYR. The formation of pyrazines is thermodynamically controlled, while 3 -oxazolines are kinetic products ${ }^{19}$. Nevertheless, under the reaction conditions of the reductive amination, the formed 3-oxazoline is unstable; it reacts with ammonia and hydrogen to form two molecules of 2-APOL ${ }^{10}$.

Hence, in the case of the single-stage reductive amination of acetol with ammonia, we can expect very fast reaction between non-reacted acetol and ammonia at the outlet from the catalytic bed. As a result of this undesirable non-catalytic reaction, by-products are formed that reduce selectivity of the amination with respect to 2-APOL. Therefore, the reductive amination of acetol with ammonia was conducted to total conversion of acetol.

\section{Materials and methods}

\section{Chemicals and catalysts}

Before use, acetol (technical grade, $90 \%$ ) purchased from Sigma-Aldrich was purified by rectification at reduced pressure $(4 \mathrm{kPa})$ on the column with oriented packing (30 theoretical plates). Distilled acetol was immediately subjected to reaction with anhydrous ammonia (Air Products and Chemicals, Inc.) in the sense of the reductive amination. Chemical stability of acetol is actually very low; even during its storage at temperature of $2{ }^{\circ} \mathrm{C}$, several auto-condensation reactions occur.

The amination of acetol was catalyzed by commercial metal catalysts based on nickel and copper. According to the manufacturer, the nickel catalyst (KL6527-CY; KataLeuna), in the form of profiled extrudates, contained $69 \% \mathrm{NiO}$, the rest was $\mathrm{Al}_{2} \mathrm{O}_{3}$ support. In addition, the copper-chromium catalyst (T-4466; Süd-Chemie) was used in the form of tablets with size of $3 \times 3 \mathrm{~mm}$ containing $53 \% \mathrm{CuO}$ and $45 \% \mathrm{Cr}_{2} \mathrm{O}_{3}$. Before use, the catalysts were first reduced in a fixed-bed reactor (in-situ) at temperature of $230{ }^{\circ} \mathrm{C}$ in a nitrogen-hydrogen atmosphere with gradually increased hydrogen concentration. Finally, the catalysts were kept at $260{ }^{\circ} \mathrm{C}$ in a hydrogen stream for an additional 18 hours.

\section{Reaction apparatus}

All experiments were carried out in the reaction apparatus shown in Fig. 1. Acetol was dosed using a peristaltic pump into the upper part of separate evaporator $\mathrm{E}\left(d_{\text {internal }}=30 \mathrm{~mm}, h=550 \mathrm{~mm}\right)$ where it was, on a layer of glass balls, evaporated in a counter-flow of hydrogen. The gaseous mixture of hydrogen and evaporated acetol flowed into glass continuous fixed-bed reactor $\mathrm{R}\left(d_{\text {internal }}=30 \mathrm{~mm}, h=\right.$ $550 \mathrm{~mm}$ ) where, just above the catalytic bed, it was mixed with ammonia. Height of the catalytic layer in the reactor was about $200 \mathrm{~mm}$; a part of the remaining space was filled with glass balls (see Fig. 1). The evaporator and the reactor were separately heated by electric heating jackets with PID regulation. Temperature in the reaction zone was monitored with a thermocouple installed in the centre of

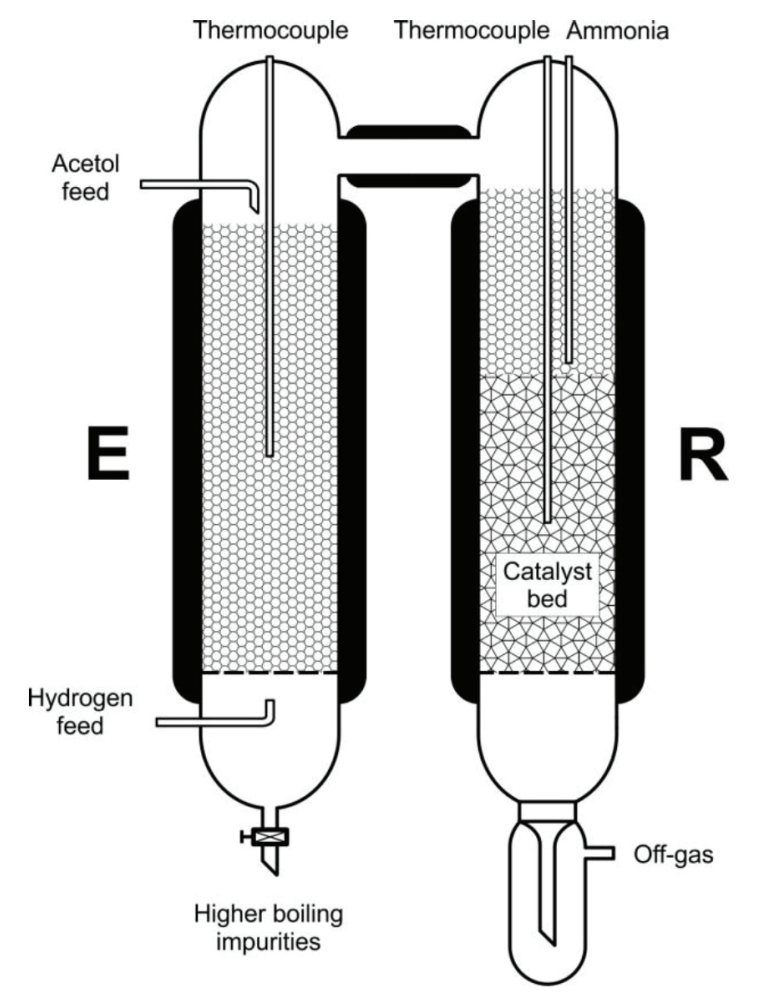

Fig. 1 - Reaction apparatus of the one-step reductive amination of acetol with ammonia in the gas phase. E: acetol evaporator; $R$ : fixed-bed reactor. 
the catalytic layer. In order to suppress the undesirable condensation of acetol, colder parts of the apparatus, in particular the route between the evaporator and reactor, were tempered. At the outlet from the reactor, the reaction mixture was condensed at temperature of about $-30{ }^{\circ} \mathrm{C}\left(\right.$ ethanol $\left./ \mathrm{CO}_{2}(s)\right)$.

\section{Experiment}

The reductive amination of acetol with ammonia was carried out in the gaseous phase under conditions of total conversion of acetol in the presence of the nickel or Adkins $(\mathrm{Cu} / \mathrm{Cr})$ catalyst. $107 \mathrm{~g}$ of the catalyst was always charged into reactor $\mathrm{R}$. The dosing rate of acetol was $8.3 \mathrm{~g} \mathrm{~h}^{-1}$. The experiments were carried out at atmospheric pressure in the presence of hydrogen at temperature of 130 (Ni catalyst) or $210{ }^{\circ} \mathrm{C}(\mathrm{Cu} / \mathrm{Cr}$ catalyst $)$. The molar excess of hydrogen and ammonia with respect to acetol ranged between 2 and 100. The temperature in the evaporator E, necessary for total evaporation of the dosed acetol, was determined by the flow-rate of hydrogen.

\section{Quantitative analysis}

Concentrations of substances were monitored by chromatographic analysis of the reaction mixtures on a gas chromatograph SHIMADZU GC 2010 equipped with FID detector and non-polar capillary column DB-5 $(60 \mathrm{~m} \times 0.32 \mathrm{~mm}$; film thickness $1 \mu \mathrm{m})$. Linear velocity of the carrier gas, helium, was $35 \mathrm{~cm} \mathrm{~s}^{-1}$. The injection port was in split mode and split ratio was 60:1. The temperature program was isothermal for $5 \mathrm{~min}$ at $80{ }^{\circ} \mathrm{C}$, then the temperature was raised to $105^{\circ} \mathrm{C}$ at a rate of $10{ }^{\circ} \mathrm{C} \mathrm{min}^{-1}$ and then raised to $250{ }^{\circ} \mathrm{C}$ at a rate of $5{ }^{\circ} \mathrm{C} \mathrm{min}^{-1}$, where it was held for $15 \mathrm{~min}$.

\section{Qualitative analysis}

The reaction products were identified by comparing their elution times with standards or by the GC/MS method on non-polar capillary column DB-1 $(35 \mathrm{~m} \times 0.32 \mathrm{~mm}$; film thickness $1 \mu \mathrm{m})$. So far unpublished mass spectra of some by-products of the reductive amination of acetol with ammonia (shown below) were obtained using a mass selective detector with $70 \mathrm{eV}$ electronic impact, $1753 \mathrm{~V}$

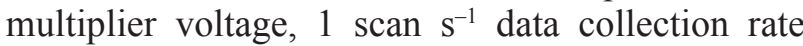
over the $\mathrm{m} / \mathrm{z}$ range of 15 to $350 \mathrm{u}$.m.a. Temperature of the ion source was $250{ }^{\circ} \mathrm{C}$. Linear velocity of the carrier gas, helium, was $35 \mathrm{~cm} \mathrm{~s}^{-1}$. The injection port was in split mode and split ratio was 60:1. The temperature program was isothermal for $3 \mathrm{~min}$ at $80{ }^{\circ} \mathrm{C}$, then the temperature was raised to $250^{\circ} \mathrm{C}$ at a rate of $5{ }^{\circ} \mathrm{C} \mathrm{min}-1$, where it was held for $15 \mathrm{~min}$.

\section{1-Ethyl-3,5-dimethylpiperazine}

MS $m / z$ (relative intensity, \%): 142 (4; $\left.\mathbf{M}^{+}\right), 98$ (1), 84 (4), 83 (2), 73 (5), 72 (100), 71 (4), 70 (6), 58 (3), 57 (6), 56 (7), 44 (16), 43 (5), 42 (24), 41 (9), $28(8)$.

\section{1-Ethyl-2,5-dimethylpiperazine}

MS $m / z$ (relative intensity, \%): $142\left(\mathbf{0} ; \mathbf{M}^{+}\right), 114(5)$, 99 (26), 84 (4), 71 (3), 70 (19), 58 (100), 57 (12), 56 (21), 44 (34), 43 (14), 42 (31), 41 (18), 40 (2), 39 (6), 30 (23), 29 (4), 28 (16).

\section{3,5-Dimethyl-1-propylpiperazine}

MS $m / z$ (relative intensity, \%): $156\left(4 ; \mathbf{M}^{+}\right), 127$ (4), 112 (3), 98 (1), 87 (6), 86 (100), 85 (6), 84 (10), 72 (1), 71 (3), 70 (14), 58 (13), 56 (7), 44 (28), 43 (13), 42 (26), 41 (14), 28 (6).

\section{2,5-Dimethyl-1-propylpiperazine}

MS m/z (relative intensity, \%): $156\left(\mathbf{5} ; \mathbf{M}^{+}\right), 127$ (6), 112 (3), 101 (7), 100 (100), 99 (4), 98 (8), 84 (10), 72 (6), 71 (4), 70 (23), $58(23), 57$ (7), $56(28)$, 44 (10), 43 (10), 42 (22), 41 (20), 30 (8), 28 (6).

\section{1-(3,5-Dimethyl-1-piperazinyl)-2-propanol}

MS $m / z$ (relative intensity, \%): $172\left(\mathbf{0 , 5} ; \mathbf{M}^{+}\right), 171$ (1), 157 (6), 128 (37), 127 (87), 112 (24), 102 (100), 101 (6), 86 (18), 85 (7), 84 (94), 72 (11), 71 (5), 70 (26), 68 (5), 59 (13), 58 (37), 57 (9), 56 (17), 45 (6), 44 (54), 43 (31), 42 (51), 41 (29), 30 (6), 28 (12), 15 (6).

\section{1-(2,5-Dimethyl-1-piperazinyl)-2-propanol}

MS $m / z$ (relative intensity, \%): $172\left(\mathbf{0 , 5} ; \mathbf{M}^{+}\right), 171$ (1), 157 (7), 127 (100), 126 (34), 116 (48), 112 (27), 98 (17), 86 (9), 84 (59), 72 (39), 71 (9), 70 (61), 58 (64), 57 (19), 56 (58), 44 (26), 43 (21), 42 (53), 41 (47), 30 (17), 28 (19).

\section{2-(3,5-Dimethyl-1-piperazinyl)propanol}

MS $m / z$ (relative intensity, \%): $172\left(\mathbf{1} ; \mathbf{M}^{+}\right), 142$ (12), 141 (84), 126 (13), 102 (100), 98 (33), 84 (35), 72 (28), 71 (6), 70 (30), 68 (6), 58 (14), 56 (40), 44 (96), 43 (14), 42 (44), 41 (32), 31 (8), 30 (8), 28 (16).

\section{2-(2,5-Dimethyl-1-piperazinyl)propanol}

MS $m / z$ (relative intensity, \%): 172 (2; $\left.\mathbf{M}^{+}\right), 157$ (2), 142 (15), 141 (100), 126 (12), 116 (56), 112 (8), 98 (23), 86 (16), 84 (53), 72 (21), 71 (7), 70 (63), 59 (9), 58 (82), 57 (19), 56 (53), 54 (6), 45 (2), 44 (29), 43 (22), 42 (43), 41 (49), 31 (14), 30 (25), 28 (27).

\section{2-(2-Aminopropylamino)propanol}

MS $m / z$ (relative intensity, \%): $132\left(\mathbf{0} ; \mathbf{M}^{+}\right), 101$ (21), 88 (78), 84 (6), 71 (6), 70 (12), 59 (8), 58 (86), 57 (9), 56 (10), 45 (3), 44 (100), 43 (10), 42 (18), 41 (25), 31 (12), 30 (83), 28 (10), 18 (14). 


\section{2-(2-Hydroxypropylamino)propanol}

MS $m / z$ (relative intensity, \%): $\mathbf{1 3 3}\left(\mathbf{0} ; \mathbf{M}^{+}\right), 118(3)$, 102 (75), 88 (83), $87(6), 86(15), 84(66), 72(3)$, $70(13), 60(13), 59(10), 58(11), 57$ (10), $56(27)$, 45 (8), 44 (35), 43 (10), $42(28), 41(53), 31(25)$, 30 (100), 29 (15), 28 (19), 18 (11).

\section{2-(2-Hydroxy-1-methylethylamino)propanol}

MS $m / z$ (relative intensity, \%): $133\left(\mathbf{0} ; \mathbf{M}^{+}\right), 102$ (49), 84 (10), 74 (2), 70 (3), 60 (4), 56 (11), 45 (3), 44 (100), 43 (9), 42 (13), 41 (11), 31 (11), 30 (4), 28 (7), $18(8)$.

\section{1-(3,5-Dimethyl-1-piperazinyl)-2-propanone}

MS $\mathrm{m} / \mathrm{z}$ (relative intensity, \%): $170\left(\mathbf{1} ; \mathbf{M}^{+}\right), 128$ (8), 127 (100), 112 (27), 110 (23), 86 (16), 85 (7), 84 (96), 72 (6), 70 (37), 68 (6), 58 (14), 56 (20), 44 (22), 43 (24), 42 (68), 41 (34), 39 (6), 28 (14), 15 (9).

\section{1-(2,5-Dimethyl-1-piperazinyl)-2-propanone}

MS $\mathrm{m} / z$ (relative intensity, \%): $170\left(\mathbf{1} ; \mathbf{M}^{+}\right), 127$ (100), 114 (7), 112 (27), 98 (9), 84 (63), 70 (53), 58 (29), 57 (9), 56 (43), 44 (22), 43 (19), 42 (51), 41 (42), 39 (8), 30 (12), 28 (19), 15 (7).

\section{1-(2-Amino-1-methylethylamino)-2-propanol}

MS $m / z$ (relative intensity, \%): $132\left(\mathbf{0} ; \mathbf{M}^{+}\right), 102$ (100), 87 (8), 84 (99), 58 (53), 57 (13), 56 (33), 45 (3), 44 (33), 43 (9), 42 (23), 41 (64), 30 (25), 28 (17), 18 (9).

\section{2-Amino-1-(2-aminopropylamino)propane}

MS $m / z$ (relative intensity, \%): $131\left(\mathbf{0} ; \mathbf{M}^{+}\right), 87$ (45), 70 (13), 58 (53), 57 (21), 56 (11), 44 (100), 42 (17), 41 (13), 30 (9), 28 (6).

\section{2-(2-Amino-1-methylethylamino)propanamine}

MS $m / z$ (relative intensity, \%): $131\left(\mathbf{0} ; \mathbf{M}^{+}\right), 101$ (62), 84 (7), 70 (5), 58 (100), 57 (9), 56 (10), 44 (48), 42 (12), 41 (32), 30 (18), 28 (10).

\section{2-(2-Aminopropylamino)propanamine}

MS $\mathrm{m} / \mathrm{z}$ (relative intensity, \%): $\left.131 \mathbf{( 0 ;} \mathbf{M}^{+}\right), 101$ (48), 87 (12), 84 (9), 70 (3), 58 (100), 56 (9), 44 (34), 42 (11), 41 (26), 30 (15), 28 (7).

\section{1-(2-Aminopropylamino)-2-propanol}

MS $m / z$ (relative intensity, \%): $132\left(\mathbf{0} ; \mathbf{M}^{+}\right), 88(41)$, 87 (15), 71 (8), 70 (33), 58 (28), 45 (6), 44 (100), 43 (13), 42 (28), 41 (19), 30 (12), 28 (6), 18 (3).

\section{1-(2-Hydroxypropylamino)-2-propanol}

MS $m / z$ (relative intensity, \%): $133\left(\mathbf{0 , 2} ; \mathbf{M}^{+}\right), 118$ (3), 88 (100), 72 (4), 71 (3), 70 (72), 58 (4), 56 (4), 45 (7), 44 (9), 43 (20), 42 (52), 41 (33), 31 (8), 30 (21), 29 (5), 28 (8), 18 (3), 15 (3).

\section{2-(2-Amino-1-methylethylamino)propanol}

MS $m / z$ (relative intensity, \%): $132\left(\mathbf{0} ; \mathbf{M}^{+}\right), 102$ (93), 101 (20), 89 (9), 88 (10), 85 (6), 84 (100), 71 (3), 70 (12), 59 (7), 58 (88), 57 (13), 56 (35), 55 (6), 45 (11), 44 (63), 43 (14), 42 (34), 41 (82), 31 (7), 30 (33), 29 (9), 28 (27), 18 (14), 15 (4).

The conversion of acetol and the selectivity of 2-APOL are defined by the following equations.

$$
\begin{aligned}
& \text { Acetol conversion }(\%)=\frac{(\text { moles of acetol in }- \text { moles of unreacted acetol })}{\text { moles of acetol in }} \cdot 100 \\
& \text { 2-APOL selectivity }(\%)=\frac{\text { moles of } 2 \text {-APOL }}{(\text { moles of acetol in }- \text { moles of unreacted acetol })} \cdot 100
\end{aligned}
$$

\section{Results and discussion}

\section{Effect of reaction conditions}

The distribution of amination products can, to a certain extent, be controlled by means of the reaction conditions (temperature, excess of ammonia, residence time) or catalyst.

\section{Effect of catalyst}

The effect of the $\mathrm{Cu} / \mathrm{Cr}$ or Ni catalysts on the reductive amination of acetol with ammonia was monitored at the molar ratio of acetol $/ \mathrm{H}_{2} / \mathrm{NH}_{3}$ $1 / 50 / 50$ and with a weight hourly space velocity (WHSV) of $0.078 \mathrm{~h}^{-1}$. It follows from the experi- mental results shown in Fig. 2 that, during the reaction on the $\mathrm{Cu} / \mathrm{Cr}$ catalyst, the concentration of required 2-APOL was, in comparison with the nickel catalyst, more than 20 times lower; major by-products of the amination were cis/trans 2,5- and 2,6-dimethylpiperazines (DMPIPs). When the Adkins catalyst was present, 2,5- and 2,6-DMPYR (DMPYRs) and 1,2-propanediamine (1,2-PDA) were also detected in a significant amount (15 respectively $8 \%$ ); whereas, in the case of the nickel catalyst, formation of these substances was almost undetectable. Nevertheless, contrary to the $\mathrm{Cu} / \mathrm{Cr}$ catalyst, 1,2-propanediol (1,2-PDOL) formed by the hydrogenation of acetol (see Scheme 7) was one of the main products $(22 \%)$ of the studied reaction when the nickel catalyst was used. 


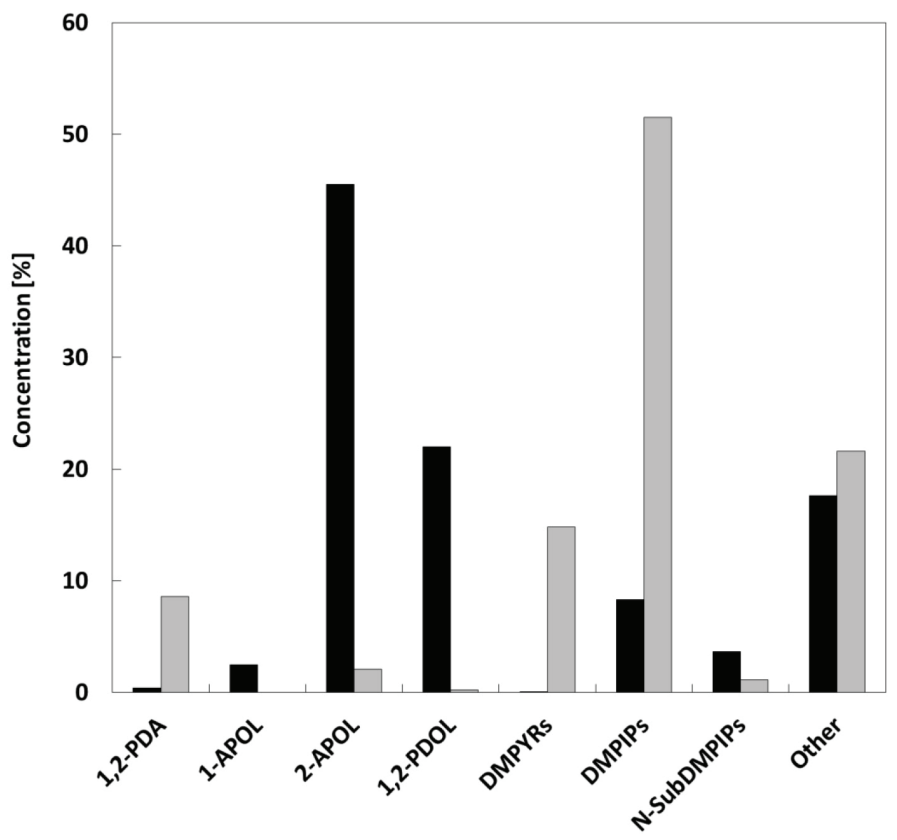

Fig. 2 - Effect of catalyst on the product distribution of the reductive amination of acetol by ammonia in the gas phase. Reaction conditions: $130{ }^{\circ} \mathrm{C}$ (Ni-based catalyst) or $210^{\circ} \mathrm{C}(\mathrm{Cu}$ $\mathrm{Cr}$ catalyst), molar ratio of acetol $/ \mathrm{H}_{2} / \mathrm{NH}_{3} 1 / 50 / 50$, WHSV = $0.078 \mathrm{~h}^{-1}$, total conversion of acetol. $\mathbf{\square}^{3}$-based catalyst (KL6527-CY); $\quad \mathrm{Cu} / \mathrm{Cr}$ catalyst (T-4466).

The product distribution of the reductive amination of acetol with ammonia can be influenced by: (1) different catalytic activity of the used metal catalysts. Compared with nickel, the catalysts based on copper show markedly lower catalytic activity in the hydrogenation of the $\mathrm{C}=\mathrm{C}$ bond; however, they are very active in condensation reactions, for example, in the condensation of imines with primary or secondary amines to form secondary and tertiary amines, respectively (Scheme 4). As a result, the presence of the copper catalyst favours formation of secondary and tertiary amines ${ }^{20}$. Moreover, the copper catalysts show high dehydrogenation activity that is increased by addition of chromium as a promoter. Chromium improves the dispersion of copper on the surface of the catalyst ${ }^{21}$ and prevents its sintering. Consequently, primary products of amination of acetol (2-APOL) can be easily dehydrogenated to very reactive $\alpha$-amino carbonyl or $\alpha$-amino imine compounds that are considered precursors of nitrogenous heterocyclic compounds (see Schemes 5 and 6). (2) The $\mathrm{Cu} / \mathrm{Cr}$ catalyst was used in the form of tablets $(3 \times 3 \mathrm{~mm})$ and, therefore, the negative effect of internal diffusion on selectivity of the amination of acetol and/or on concentration of 2-APOL is not excluded. Hence, outside the catalyst tablet, various side reactions of very reactive intermediate imines and amination products can proceed, for example, a bimolecular cycloamination of primary amino alcohols (1-APOL, 2-APOL) or 1,2-PDA with formation of relevant pyrazines and/

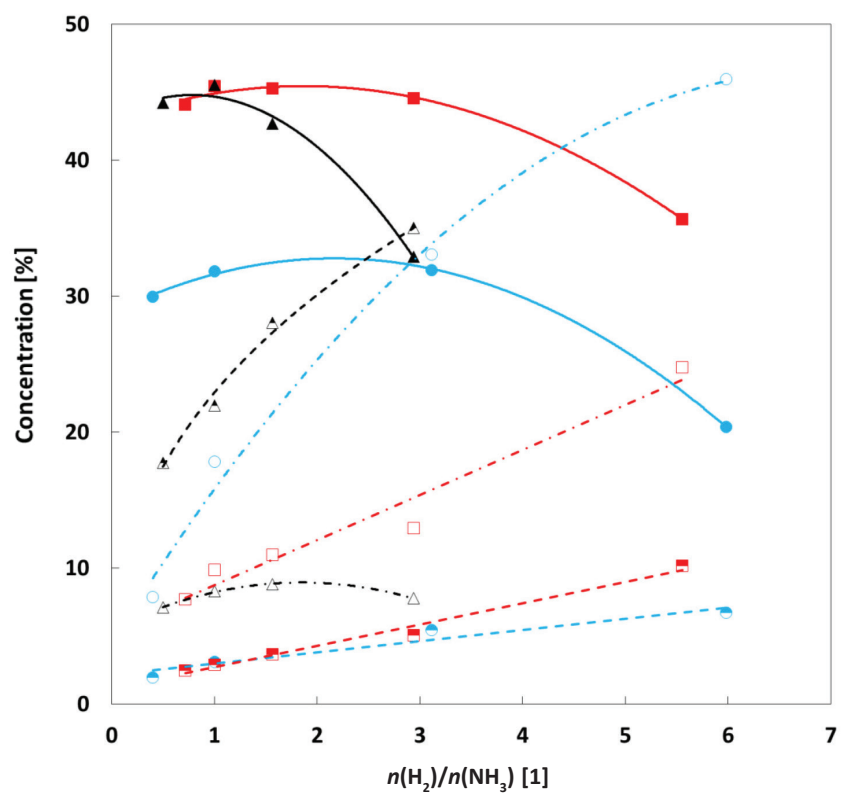

Fig. 3 - Concentration of 2-APOL (full points), 1,2-PDOL (half full points) and DMPIPs (empty points) as a function of the molar ratio of $n\left(\mathrm{H}_{2}\right) / n\left(\mathrm{NH}_{3}\right)$ at varied molar excess of hydrogen with respect to acetol $n\left(H_{2}\right) / n($ acetol $)-14$ (circles), 25 (squares) and 50 (triangles). Reaction conditions: $130{ }^{\circ} \mathrm{C}$ ( Nibased catalyst), WHSV $=0.078 \mathrm{~h}^{-1}$, total conversion of acetol.

or piperazines. (3) Different distribution of products can also be caused by process temperature of the catalysts used. In the case of the nickel catalyst, the reaction was conducted at a temperature of $130{ }^{\circ} \mathrm{C}$. Generally, the Adkins catalysts show lower activity $^{20}$ that was compensated by increasing the reaction temperature to $210^{\circ} \mathrm{C}$. Higher reaction temperature results in the formation of thermodynamically more stable secondary, tertiary or cyclic amines with six-membered ring (pyrazines and/or piperazines). Actually, the formation of these substances is exothermic, whereas the reaction leading to primary amines is nearly thermoneutral ${ }^{5,22}$.

The formed DMPIPs contain secondary nitrogen atoms in their molecules and, therefore, they can subsequently undergo the reductive amination to $N$-mono- or $N, N$-di-substituted dimethyl piperazines ( $N$-SubDMPIPs).

\section{Effect of molar ratio of acetol/hydrogen/ammonia}

The effect of the molar ratio of acetol/hydrogen/ammonia on the course of the reductive amination of acetol was monitored in the presence of the $\mathrm{Ni}$ catalyst at a temperature of $130{ }^{\circ} \mathrm{C}$. Fig. 3 shows the dependence of concentrations of 2-APOL, DMPIPs and 1,2-PDOL on the molar ratio of $\mathrm{H}_{2} / \mathrm{NH}_{3}(0.4$ to $6)$ at varied molar excess of hydrogen with respect to acetol $\left(n\left(\mathrm{H}_{2}\right) / n(\right.$ acetol $)=14 ; 25$ and 50$)$.

The results presented in Fig. 3 show that the increasing excess of hydrogen with respect to acetol 
has a positive influence on concentration of 2-APOL and markedly suppresses formation of the most important by-products of the reductive amination of acetol, i.e. DMPIPs. Based on the general mechanism of the reductive amination, we assign this effect to the chemical equilibrium shift of the proceeding hydrogenation-dehydrogenation reactions with respect to saturated products. Hence, as a result of the hydrogen excess, the hydrogenation of the intermediate imine to 2-APOL is preferred (Scheme 1), and the dehydrogenation of the formed primary $\alpha$-amino propanols (1-APOL, 2-APOL) to $\alpha$-amino carbonyl compounds, as precursors of nitrogenous heterocyclic substances, is markedly suppressed. Nevertheless, concerning concentration of 2-APOL, the significant molar excess of hydrogen with respect to acetol is not higher than 25 . With the molar ratio of hydrogen/acetol 25 and 50 (full squares or full triangles), almost the same content of 2-APOL was found in the organic phase, about $45 \%$, at the most. In addition, with the 50 times molar excess of hydrogen, the extent of the competitive hydrogenation of acetol to undesirable 1,2PDOL (half full points) was markedly increased. In this case, in comparison with other experiments, the concentration of 1,2-PDOL was by several orders of magnitude higher; and when the molar ratio of hydrogen/ammonia increased to 3 , the hydrogenation was a dominant reaction of the studied reaction system. This fact indicates a marked decrease in concentration of 2-APOL to as low as $30 \%$, whereas almost one third of the reaction mixture was $1,2-$ PDOL.

It is generally known that the excess of ammonia has a positive effect on selectivity of amination reactions to primary amines ${ }^{5,23-26}$. This method markedly suppressed formation of undesirable secondary and tertiary amines during the reductive amination of acetol. As it is shown in Fig. 3, in experiments less influenced by the hydrogenation of acetol $\left(n\left(\mathrm{H}_{2}\right) / n\right.$ (acetol $)-14$ - empty circles and 25 - empty squares), the concentration of DMPIPs was almost proportionally dependent on the increasing molar ratio of hydrogen/ammonia, whereas the content of 2-APOL showed a moderate decrease. In the course of amination with the fourteen times excess of hydrogen with respect to acetol and the molar ratio of hydrogen/ammonia higher than 3, DMPIPs were dominant products.

Increased selectivity of the amination to primary amine caused by the excess of ammonia can be explained by the addition of $\mathrm{NH}_{3}$ on intermediate primary imine with formation of gem-diamine that is subsequently hydrogenolyzed to primary amine (Scheme 3$)^{27}$. Hence, the very reactive imine is protected against subsequent reactions to secondary and tertiary amines (Scheme 4). In compliance with this mechanism, the competitive reaction with ammonia reduces the concentration of primary imine in the reaction system and, thus, also the rate of formation of side secondary amines ${ }^{20}$.

The dependence of concentration of other identified by-products formed during the reductive amination of acetol with ammonia on the molar ratio of reactants is shown in Table 1. However, most of these compounds contain two or three stereogenic centres in their molecules and, therefore, they can theoretically form four or eight stereoisomers (two or four pairs of enantiomers). Nevertheless, chromatographic analysis identified just two or four diastereoisomers cis and trans in the reaction mixture. Concentrations of individual substances include all possible isomers in Table 1.

The experimental results presented above show that, concerning selectivity to required 2-APOL, the optimal molar ratio of $\mathrm{H}_{2} / \mathrm{NH}_{3}$ was 1 . Hence, the reductive amination of acetol with ammonia should not be conducted with a higher amount of substance of hydrogen with respect to ammonia.

\section{Side products}

The presented results indicate that, in the course of the one-step reductive amination of acetol with ammonia, a large number of various by-products (primary, secondary and tertiary amines, amino alcohols, polyamines, heterocyclic compounds) are formed, the most important are $C$-dimethyl-piperazines (2,5- and 2,6-DMPIP). Thus, this is a very complex reaction system including many subsequent, side, and condensation side reactions of intermediates ( $\alpha$-amino carbonyl compounds, imines, enamines) or amination products (amines, amino alcohols). These substances are, compared with ammonia, more nucleophilic and, therefore, more reactive in the amination ${ }^{5,7}$.

Due to the $\alpha$-hydroxy carbonyl group, acetol can, in the same way as reducing sugars ${ }^{28}$, easily react with ammonia to various heterocyclic substances through the so-called Maillard reaction ${ }^{29}$. This is a typical non-enzymatic reaction in the food chemistry between reducing sugars and substances containing primary amino group (proteins, amino acids, peptides) during thermal processing of foods. Products of this reaction are sensory active substances, like all alkylated pyrazines ${ }^{28-34}$. Precursors of these substances are very reactive $\alpha$-amino carbonyl compounds $\left(\mathrm{R}-\mathrm{CH}\left(\mathrm{NH}_{2}\right)-\mathrm{C}(=\mathrm{O})-\mathrm{R}\right)$.

Compounds derived from 2-hydroxypropanal (2-HPAL), e.g. 1-APOL, 1-(3,5-dimethyl-1-piperazinyl)-2-propanol and 1-(2,5-dimethyl-1-piperazinyl)2-propanol (Table 1), were also detected in the reaction mixtures. Therefore, we assume that, in the course of amination, acetol undergoes 1,2- and 
Table 1 -Concentration of other identified by-products (without DMPIPs) formed during the reductive amination of acetol with ammonia in the gas phase over nickel catalyst. Conditions: $130^{\circ} \mathrm{C}$; WHSV $=0.078 \mathrm{~h}^{-1}$; total conversion of acetol.

\begin{tabular}{|c|c|c|c|c|c|c|c|c|c|c|c|c|c|}
\hline$n($ acetol $) / n\left(\mathrm{H}_{2}\right)$ & \multicolumn{4}{|c|}{14} & \multicolumn{5}{|c|}{25} & \multicolumn{4}{|c|}{50} \\
\hline$n($ acetol $) / n\left(\mathrm{NH}_{3}\right)$ & 35 & 14 & 4.5 & 2.3 & 35 & 25 & 16 & 8.5 & 4.5 & 100 & 50 & 32 & 17 \\
\hline$n\left(\mathrm{H}_{2}\right) / \mathrm{n}\left(\mathrm{NH}_{3}\right)$ & 0.4 & 1.0 & 3.1 & 6.1 & 0.7 & 1.0 & 1.6 & 2.9 & 5.6 & 0.5 & 1.0 & 1.6 & 2.9 \\
\hline Compound & \multicolumn{13}{|c|}{ Concentration $(\%)$} \\
\hline 1,2-PDA & 5.89 & 1.90 & 0.98 & - & 2.16 & 0.96 & - & - & - & 0.41 & 0.40 & - & - \\
\hline 1-APOL & 1.92 & 2.31 & 2.18 & 1.76 & 2.24 & 2.19 & 2.30 & 1.61 & 1.79 & 2.54 & 2.46 & 2.26 & 1.26 \\
\hline Isopropenyl acetate & 0.02 & 0.04 & 0.05 & 0.08 & 0.02 & 0.03 & 0.04 & 0.05 & 0.10 & 0.02 & 0.04 & 0.05 & 0.11 \\
\hline 1-(Ethylamino)-2-(methylamino)ethane & 0.12 & 0.52 & 1.08 & 1.70 & 0.33 & 0.34 & 0.37 & 0.51 & 0.74 & 0.30 & 0.31 & 0.35 & 0.31 \\
\hline$N$-Ethyl(2-methoxyethyl)amine & 0.05 & 0.10 & 0.21 & 0.42 & 0.04 & 0.08 & 0.11 & 0.17 & 0.25 & 0.02 & 0.05 & 0.08 & 0.15 \\
\hline 1-(Ethylamino)-2-propanol & 0.05 & 0.17 & 0.29 & 0.35 & 0.12 & 0.18 & 0.18 & 0.19 & 0.23 & 0.03 & 0.05 & 0.08 & 0.14 \\
\hline 2-(Ethylamino)propanol & - & 0.06 & 0.34 & 0.95 & 0.04 & 0.04 & 0.05 & 0.11 & 0.41 & 0.12 & 0.20 & 0.32 & 0.43 \\
\hline 2,6-Dimethyl-1,4-dihydropyrazine & 0.13 & 0.02 & 0.08 & 0.02 & 0.06 & 0.02 & 0.02 & - & - & 0.02 & 0.03 & 0.02 & - \\
\hline 2,5-Dimethyl-1,4-dihydropyrazine & 0.22 & 0.08 & 0.16 & 0.01 & 0.10 & 0.05 & 0.05 & 0.01 & - & 0.08 & 0.09 & 0.06 & 0.02 \\
\hline 2,6-DMPYR & - & 0.01 & 0.06 & 0.11 & - & - & - & - & - & - & - & - & - \\
\hline 2,5-DMPYR & 0.09 & 0.13 & 0.06 & 0.07 & 0.02 & 0.02 & 0.03 & 0.03 & - & 0.03 & 0.02 & 0.01 & - \\
\hline 2,5-Dimethyl-1 $H$-pyrrole & 0.01 & 0.04 & 0.08 & 0.13 & - & 0.02 & 0.03 & 0.03 & 0.02 & 0.01 & 0.01 & 0.02 & 0.02 \\
\hline 2,4-Dimethyl-1 $H$-pyrrole & 0.08 & 0.21 & 0.04 & 0.10 & 0.14 & 0.10 & 0.13 & 0.12 & 0.04 & 0.19 & 0.12 & 0.09 & 0.02 \\
\hline 1-Ethyl-3,5-dimethylpiperazine & 9.69 & 2.76 & 0.30 & 0.62 & 2.65 & 0.98 & 0.77 & 0.48 & 0.18 & 1.81 & 0.74 & 0.32 & 0.39 \\
\hline 1-Ethyl-2,5-dimethylpiperazine & 0.15 & 0.32 & 1.04 & 2.70 & 0.11 & 0.09 & 0.16 & 0.28 & 0.73 & 1.97 & 1.11 & 0.86 & 0.48 \\
\hline 3,5-Dimethyl-1-propylpiperazine & 0.02 & 0.02 & 0.03 & 0.03 & 0.03 & 0.02 & 0.02 & 0.03 & 0.02 & 0.16 & 0.08 & 0.09 & 0.12 \\
\hline 2-(2-Aminopropylamino)-propanol & 1.92 & 0.61 & 0.37 & - & 1.82 & 1.44 & 1.36 & 1.07 & 0.01 & 0.40 & 0.62 & 0.39 & 0.44 \\
\hline 2-(2-Hydroxypropylamino)-propanol & 0.40 & 0.13 & 0.18 & 0.06 & 0.54 & 1.45 & 0.68 & 0.47 & 0.22 & 1.28 & 1.29 & 1.17 & 1.83 \\
\hline 2-(2-Hydroxy-1-methylethylamino)propanol & 1.34 & - & 0.13 & 0.08 & 1.86 & 2.37 & 1.75 & 1.27 & 0.14 & 3.98 & 4.71 & 4.1 & 6.05 \\
\hline 1-(3,5-Dimethyl-1-piperazinyl)-2-propanol & 1.01 & 1.68 & 1.37 & 0.84 & 0.79 & 1.12 & 1.48 & 1.69 & 1.66 & 0.57 & 0.46 & 0.65 & 0.68 \\
\hline 1-(2,5-Dimethyl-1-piperazinyl)-2-propanol & 12.31 & 5.31 & 2.42 & 1.53 & 6.36 & 6.53 & 6.68 & 6.23 & 1.59 & 1.21 & 0.89 & 0.95 & 1.03 \\
\hline 2-(3,5-Dimethyl-1-piperazinyl)propanol & 1.92 & 6.06 & 2.42 & 2.61 & 3.83 & 4.14 & 4.14 & 3.83 & 3.35 & 1.34 & 0.91 & 1.13 & 1.39 \\
\hline 2-(2,5-Dimethyl-1-piperazinyl)propanol & 8.10 & 13.96 & 7.48 & 5.68 & 6.46 & 10.94 & 9.34 & 8.07 & 13.10 & 2.82 & 2.86 & 3.23 & 4.39 \\
\hline
\end{tabular}


Table 2 - Boiling point (BP) and melting point (MP) of diastereoisomers cis/trans 2,5- and 2,6-DMPIP

\begin{tabular}{l|c|c}
\hline Piperazine isomer & $\mathrm{BP}_{101,325 \mathrm{kPa}}\left({ }^{\circ} \mathrm{C}\right)$ & $\mathrm{MP}\left({ }^{\circ} \mathrm{C}\right)$ \\
\hline cis-2,5-DMPIP & $162^{45,48}$ & $18^{45} ; 114^{48}$ \\
trans-2,5-DMPIP & $160-165^{45,48}$ & $115-118^{45,48}$ \\
cis-2,6-DMPIP & $161-162^{49}$ & $113-114^{47,49}$ \\
trans-2,6-DMPIP & $180^{49}$ & $105-108^{49}$ \\
\hline
\end{tabular}

2,3-enolization (1,2-E a 2,3-E) by means of acidic $\alpha$-hydrogens with formation of enol (E1) and enediol (E2) that are in equilibrium with 2-HPAL ${ }^{35}$.

Scheme 5 shows potential reaction pathways of formation of by-products detected in the reaction mixture during the amination of acetol with ammonia in the presence of the Ni catalyst, as a result of enolization of acetol and rearrangement of the primarily formed labile $\alpha$-hydroxy imines.

2-HPAL and acetol react with ammonia via the reductive amination, first to hemiaminals that are stabilized by the loss of one molecule of water to form the corresponding Schiff base 1-imino-2-propanol (1-IPOL) or 2-iminopropanol (2-IPOL). Under the reaction conditions, these labile $\alpha$-hydroxy imines are hydrogenated to 1-APOL and the desired 2-APOL, or they are stabilized by the Amadori ${ }^{36}$ and Heyns ${ }^{37,38}$ rearrangements to corresponding $\alpha$-amino carbonyl compounds, i.e. 1-amino-2-propanone (1-APON) or 2-aminopropionaldehyde (2APAL). The hydroxy group bound to $\alpha$-carbon in the molecules of 2-IPOL and 1-APON facilitates the 1,3-hydrogen shift (imine-enamine tautomerism $^{39,40}$ ) and, simultaneously, stabilizes the formed enamines (EN1 and EN2) ${ }^{41,42}$ that subsequently undergo keto-enol tautomerism ${ }^{43,44}$ with formation of 2-APAL (Heyns product) or 1-APON (Amadori product). These intermediates can also be formed by dehydrogenation of the produced amino alcohols (1-APOL and 2-APOL) on the surface of the metal catalyst.

Intermediate $\alpha$-amino carbonyl compounds (1APON and 2-APAL) can also react with ammonia to 2-iminopropanamine (2-IPA) or 1-imino-2-propanamine (1-IPA) that subsequently react to form heterocyclic substances or are hydrogenated to 1,2PDA.

The bimolecular cycloamination of $\alpha$-amino carbonyl or $\alpha$-imino amine compounds produces corresponding $\quad C$-dimethyl-1,4-dihydropyrazines that undergo dehydrogenation to $2,5-$ and/or 2,6-DMPYR, or they are hydrogenated to 2,5- and 2,6-DMPIP. $C$-Dimethylpiperazines form diastereoisomers cis and $\operatorname{trans}^{45-49}$ with similar physical properties (see Table 2). In order to separate them on capillary column DB-5, the isomers were first deri- vatized with acetanhydride to corresponding acetamides $^{46}$ and subsequently analyzed by GC. Reaction Scheme 5 only shows the general position of the methyl groups (wavy bonds) with respect to the plane of the ring.

In the Maillard reaction, $\alpha$-amino carbonyls are considered precursors of not only pyrazines and/or piperazines but also of other unsaturated heterocyclic compounds, such as oxazolines ${ }^{17-19,30,50}$, oxazoles $^{29,30,50,51}$, imidazoles ${ }^{28-31,50}$, imidazolines ${ }^{50,52}$, or pyrroles $^{29,30,51,53}$ (see Scheme 6). Nevertheless, under the reaction conditions of the reductive amination, oxazolines are unstable and react with the amination agent and hydrogen to form two molecules of corresponding $\alpha$-amino alcohols ${ }^{10}$. Similarly, vicinal diamines can be formed from imidazolines.

Nevertheless, most of the undesirable substances are apparently formed due to side reactions of amination products that contain reactive primary (1and 2-APOL or 1,2-DAP) or secondary (2,5- and 2,6-DMPIP) amino groups in their molecule. These "new" amination agents react subsequently with $\alpha$-hydroxy- and $\alpha$-amino carbonyl compounds or formed $\alpha$-amino alcohols to corresponding amino compounds with secondary or tertiary amino group.

Scheme 7 shows the side amination reactions of acetol and 2-HPAL with substances containing the primary amino group (the compounds identified in the reaction mixture are shown in bold). The amination produces corresponding stereoisomers of secondary aliphatic dihydroxy amines, hydroxy diamines or triamines. The same substances can also be produced by condensation of formed $\alpha$-amino propanols (1- and 2-APOL) and 1,2-PDA by means of the primary amino groups with subsequent loss of one molecule of water or $\mathrm{NH}_{3}$ (the reactions of primary amines with imines are not shown in the scheme ${ }^{23}$. Dihydroxy amines and hydroxy diamines react with ammonia to hydroxy diamines and triamines that easily undergo intramolecular condensation (amination) to 2,5- or 2,6-DMPIP. Actually, the position of primary functional groups $\left(-\mathrm{NH}_{2}\right.$, $-\mathrm{OH})$ in the molecule of hydroxy diamine and triamine is favourable for formation of the thermodynamically stable six-membered ring. 2,5- and 2,6-DMPIP can also be formed through the bimolecular cycloamination of 1-APOL, 2-APOL or 1,2DAP $^{45-49}$. Similarly to Scheme 5 , only the general position of methyl group is depicted in the stereoisomeric molecules (wavy bonds).

Another important side reaction is the competitive hydrogenation of acetol to 1,2-PDOL. 1-(Ethylamino)-2-propanol and 2-(ethylamino)propanol were also detected in the reaction mixture (see Table 1). Formation of these substances can be explained by the reaction of acetaldehyde with both 1-APOL and/or 2-APOL, and with ammonia to eth- 
yl amine that subsequently reacts with acetol or 2-HPAL. Acetaldehyde is probably generated in the reaction phase by hydrogenolysis of acetol on the surface of the Ni catalyst.

Scheme 8 shows side reactions of $\alpha$-hydroxy carbonyl and carbonyl (acetaldehyde, propionaldehyde) compounds that can explain the formation of $\mathrm{N}$-substituted 2,5- and 2,6-DMPIP identified (shown in bold) during the amination of acetol with $\mathrm{NH}_{3}$ in the presence of metal catalyst.

Acetol and 2-HPAL react with piperazines through the reductive amination, first to enamines that are hydrogenated to corresponding tertiary amines. As enamines contain the $\pi$-bond between carbon atoms with hydroxy group (enol form) in their molecule, keto-enol tautomerization with the formation of amino carbonyl compounds (keto form) is also assumed ${ }^{43,44}$. However, these substances were not detected in the reaction mixture. In the molecule of 2,6-DMPIP, one of the nitrogen atoms is sterically hindered by methyl groups bound to neighbouring carbons; the amination reaction on such nitrogen is less probable. Thus, the nucleophilic addition of 2,6-DMPIP to the carbonyl group is exclusively caused by the sterically less hindered nitrogen atom. In addition, substances (such as 3,5-dimethyl-1-propylpiperazine) were identified in the reaction mixture that indicate dehydration of 1,2-PDOL to propionaldehyde (PAL); formation of propanone (PON) is also possible.

The produced substances form diastereoisomers cis/trans that are not distinguished in the reaction scheme and only the general position of methyl groups is shown (wavy bonds).

$\mathrm{N}$-monosubstituted DMPIPs contain one more secondary nitrogen atom and, therefore, they can subsequently react with $\alpha$-hydroxy carbonyl and carbonyl compounds to $N, N$-disubstituted DMPIPs. Nevertheless, in the molecule of $N$-monosubstituted 2,6-DMPIP, the secondary nitrogen atom is sterically hindered by methyl groups in positions $\mathrm{C} 2$ and $\mathrm{C} 6$, and, therefore, another amination via such nitrogen is quite unlikely.

The produced secondary and tertiary amines contain also primary functional groups $\left(-\mathrm{NH}_{2}\right.$ and $-\mathrm{OH})$ that can undergo the hydrogenation amination. The result of the subsequent amination reactions can then be brown to black high molecular weight polymeric nitrogen compounds (polyalkylene-polyamines and polyalkylene-polyhydroxy- polyamines), of often unknown structure, so-called melanoidines. Other types of potential side reactions can be: (1) aldolization reaction of carbonyl compounds, (2) disproportionation of amines ${ }^{2,54-56}$, (3) deamination of amines, or (4) dehydrogenation of intermediate imines to corresponding nitriles ${ }^{1,57}$. These reactions are not shown in the simplified reaction schemes.

Nevertheless, most of the potential by-products shown in Schemes 5 to 8 were not detected during the reductive amination of acetol with ammonia at all. In such complex reaction mixtures of substances with similar physical properties (boiling point), elution peaks of individual compounds are often overlapped in the chromatographic analysis on a non-polar column.

\section{Conclusions}

The one-step reductive amination of acetol with ammonia in the gaseous phase was catalysed by commercial catalysts based on $\mathrm{Ni}$ and $\mathrm{Cu} / \mathrm{Cr}$. With both catalysts, relatively low selectivity to the desired 2-APOL at total conversion of acetol was observed. In the case of the nickel catalyst, selectivity to $2-\mathrm{APOL}$ was about $45 \%$ at most, whereas it was only $8 \%$ with the $\mathrm{Cu} / \mathrm{Cr}$ catalyst. Nevertheless, concerning the selectivity to 2-APOL, the optimal molar ratio of $\mathrm{H}_{2}$ /acetol is 25 . Its further increase favours the competitive hydrogenation of acetol to 1,2-PDOL and the selectivity to 2-APOL decreases sharply. Therefore, the reaction should not be led with a molar excess of hydrogen towards ammonia. The optimal molar ratio of $\mathrm{H}_{2} / \mathrm{NH}_{3}$ was 1 .

The reaction mixture contained predominantly aliphatic or cyclic secondary and tertiary amines, and other non-identified highly condensed by-products, the most important were cis/trans 2,5- and 2,6-DMPIP. In the studied reaction system, various side reactions proceed, such as enolization of acetol, deamination, aldolization, subsequent reactions of amination products, Heyns and Amadori rearrangements or Maillard reaction.

\section{ACKNOWLEDGEMENT}

Financial support from specific university research (MSMT No 20-SVV/2016). 


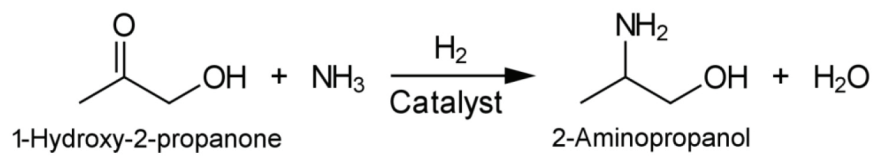

Scheme 1 - Reductive amination of acetol by ammonia to 2-APOL

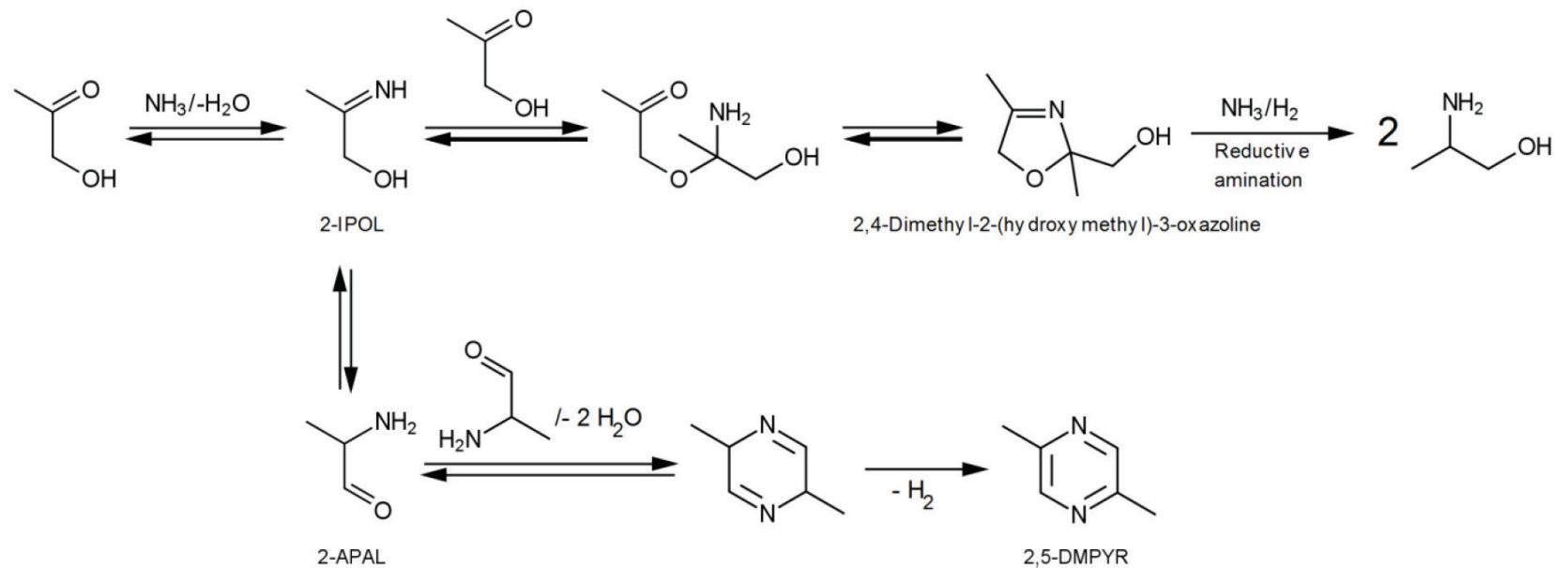

Scheme 2 -Non-catalytic reaction of acetol by ammonia to form 2,5-DMPYR and 2,4-dimethyl-2-(hydroxymethyl)-3-oxazoline and the reductive amination of the resulting 3-oxazoline to $2-A P O L^{10,19}$

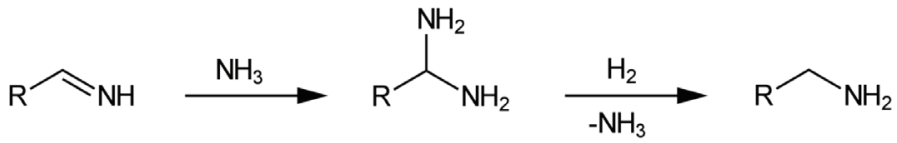

Scheme 3 - Mechanism proposed by Schwoegler and Adkins explaining the effect of ammonia on the selectivity to primary amines in the reductive amination of aldehydes with ammonia ${ }^{27}$

$\overbrace{\mathrm{NH}}+\mathrm{R}_{\mathrm{NH}_{2}}$<smiles>[R]C=[NH+][CH]CNC[R]</smiles>

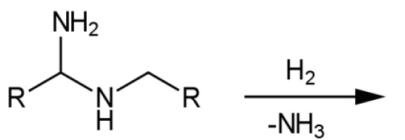<smiles>[R]CNC[R]</smiles><smiles>[R]CN(C[R])C([R])N</smiles><smiles>[R]CN(C[R])CC</smiles>

Scheme 4 - Mechanism of the formation of secondary and tertiary amines from primary intermediate imine ${ }^{27}$ 


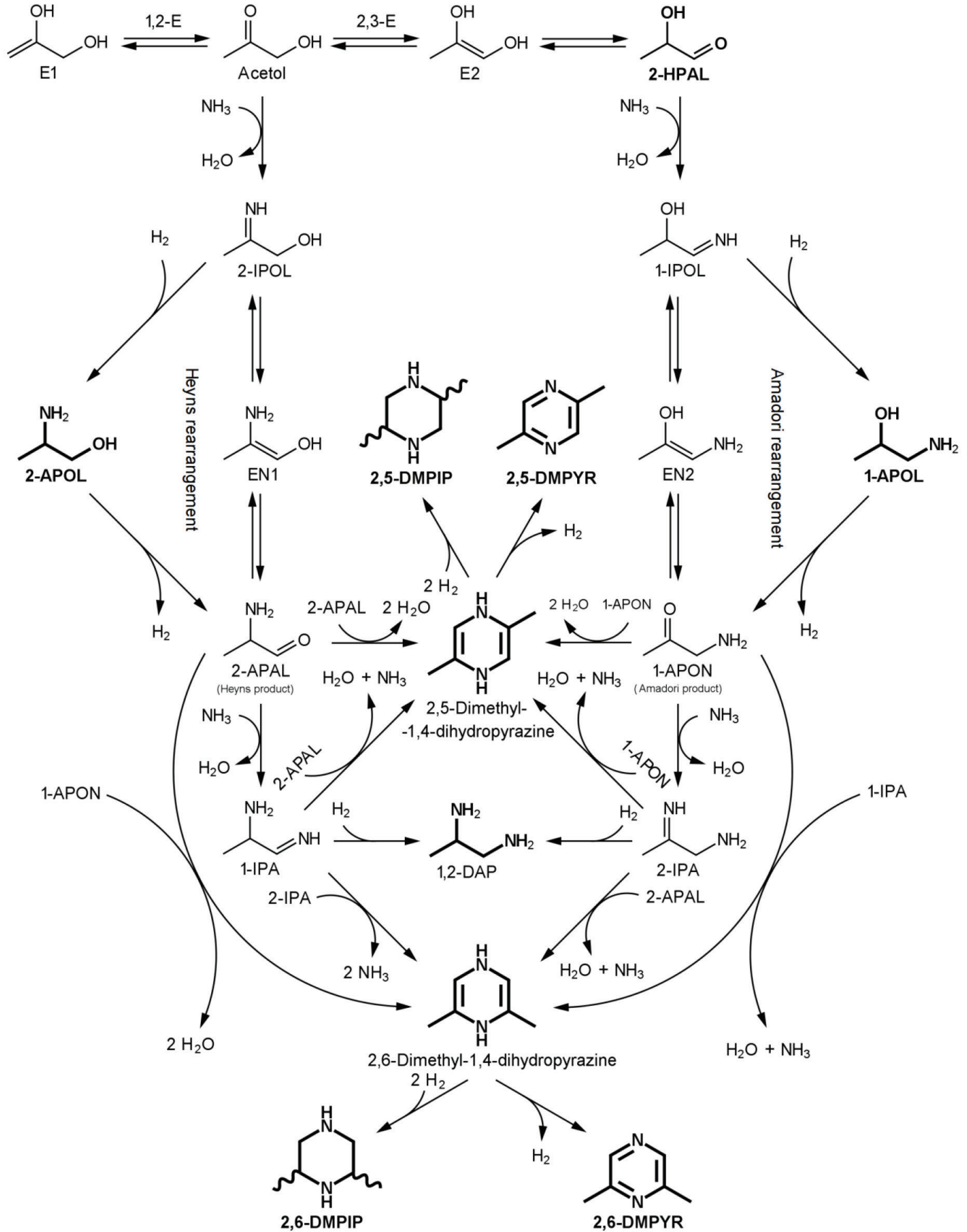

Scheme 5 -Formation of 1-APOL, 1,2-DAP, 2,5- and 2,6-DMPYR and 2,5- and 2,6-DMPIP in the reductive amination of acetol by ammonia due to 2,3-enolization of acetol and tautomerization of the primarily formed $\alpha$-hydroxy imines (2-IPOL and 1-IPOL). The compounds detected in the reaction mixtures are shown in bold. 
<smiles>[R]c1[nH]c([R2])c([R])c1[R]</smiles>

Pyrroles<smiles>[R]C(=O)C([R3])C([R])(O)C([R])N</smiles><smiles>[R3]CC(=O)OCC</smiles>

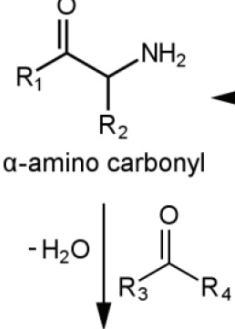<smiles>[R5]N=C([R])NC([R])[R]</smiles><smiles>C=[R5](N)[14OH]</smiles><smiles>[R]C(=O)C([R2])N=C([R])[R]</smiles><smiles>CCCCC</smiles>
$-\mathrm{H}_{2} \mathrm{O} \mid \begin{aligned} & \mathrm{R}_{3}=\mathrm{H} \\ & \mathrm{R}_{4}=\text { hydroxyalkyl }\end{aligned}$

Reductive amination<smiles>[R]C(O)C([R])N([R])[R]</smiles><smiles>[R]C1=NC([R])([R])N([R5])C1[R]</smiles>
Imidazolines $-\mathrm{H}_{2} \mathrm{O} \mid \begin{aligned} & \mathrm{R}_{3}=\mathrm{H} \\ & \mathrm{R}_{4}=\text { hydroxyalkyl }\end{aligned}$<smiles>[R]c1nc([R])n([R5])c1[R]</smiles>

Imidazoles

$\mathrm{R}_{4}=\mathrm{alkyl}$<smiles>[R]C1=NC([R])([R3])OC1[R]</smiles>

\section{Oxazolines}

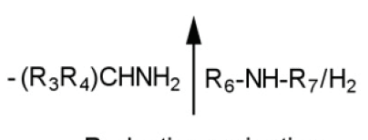

Reductive amination<smiles>[R]c1nc([R])c([R])o1</smiles>

Oxazoles

$\mathrm{R}_{4}=\mathrm{alkyl}$ $R_{1-7}=H$, alkyl, hydroxyalkyl

$\mathrm{Scheme} 6$-Formation of five-membered heterocyclic compounds by the reaction of $\alpha$-amino carbonyl and carbonyl compounds 


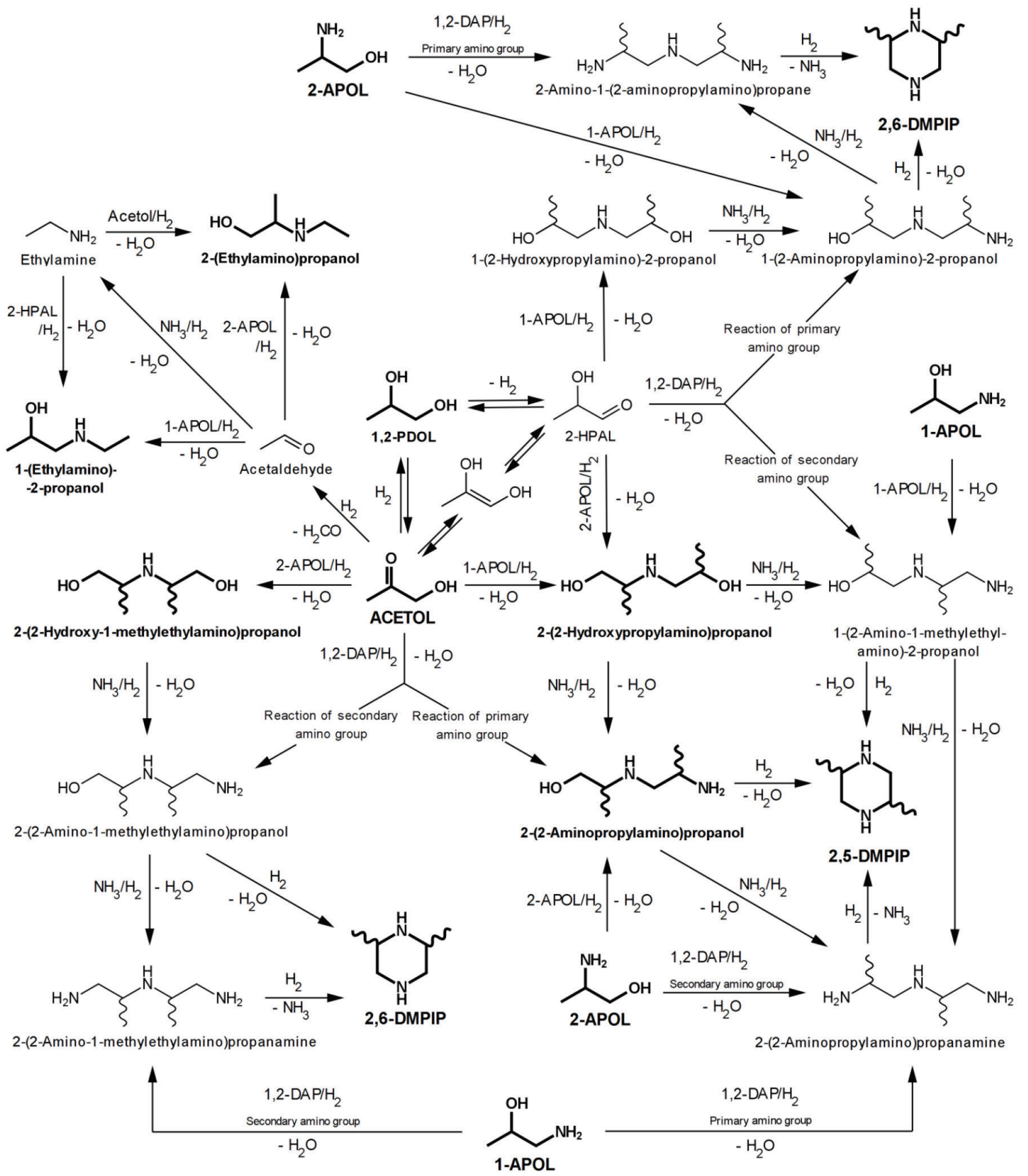

Scheme 7 - Formation of secondary aliphatic (dihydroxy amines, hydroxy diamines and triamines) and heterocyclic (2,5- and 2,6-DMPIP) amino compounds in the reductive amination of acetol with ammonia due to side amination reactions of formed primary $\alpha$-amino propanols (1- and 2-APOL) and 1,2-DAP 

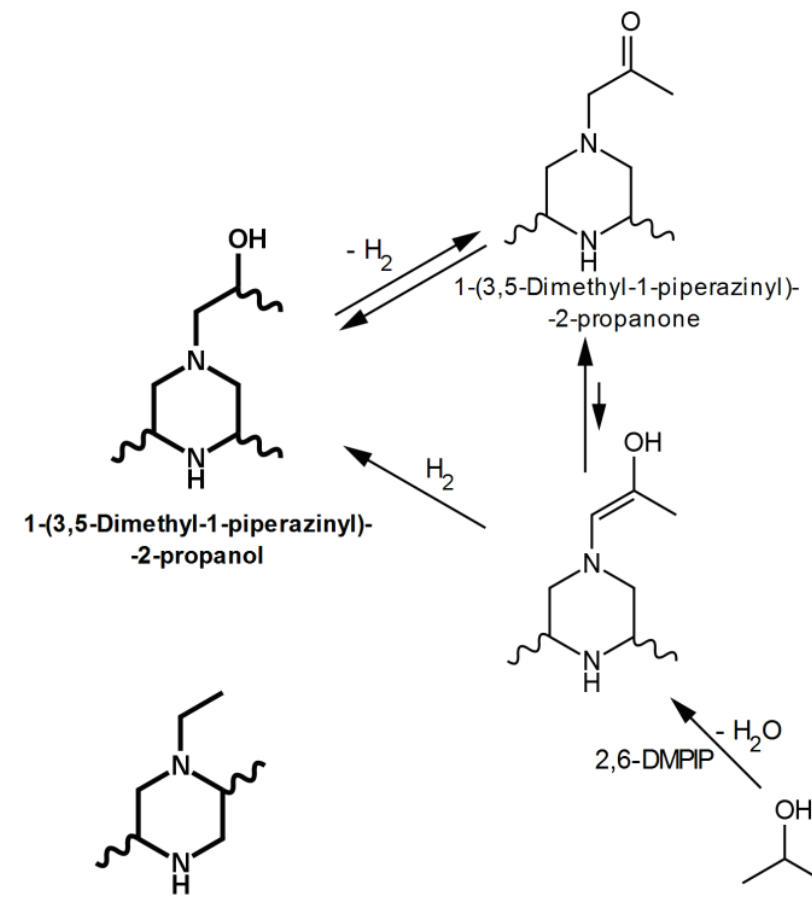

1-Ethyl-2,5-dimethylpiperazine

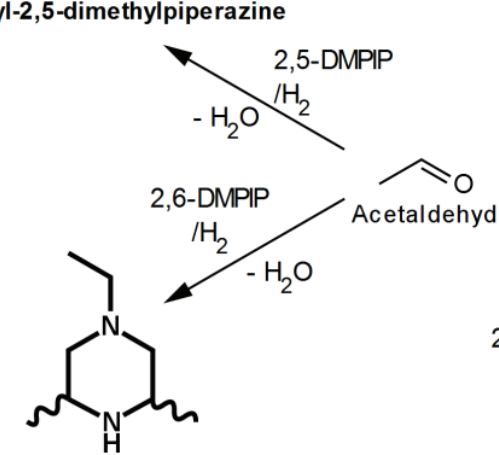

$$
\text { -2-propanone }
$$

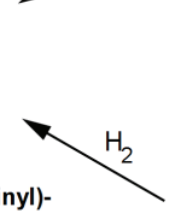

(-propanon

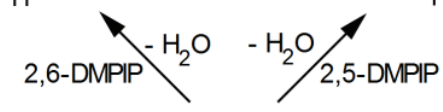

$\mathrm{OH}$<smiles>CC(O)C=O</smiles>

2-HPAL
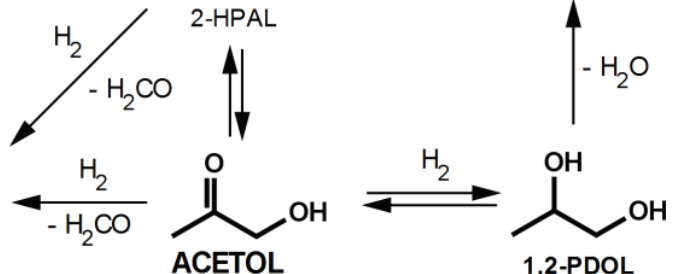

$\overbrace{P O N}^{O}$

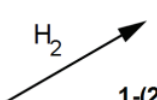

1-(2,5-Dimethyl-1-piperazinyl)-2-propanol

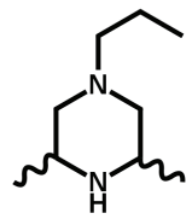

3,5-Dimethyl-1-propylpiperazine

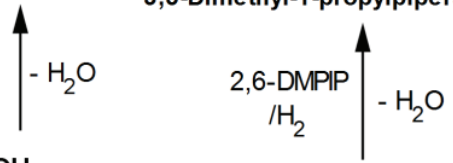

2-PDOL
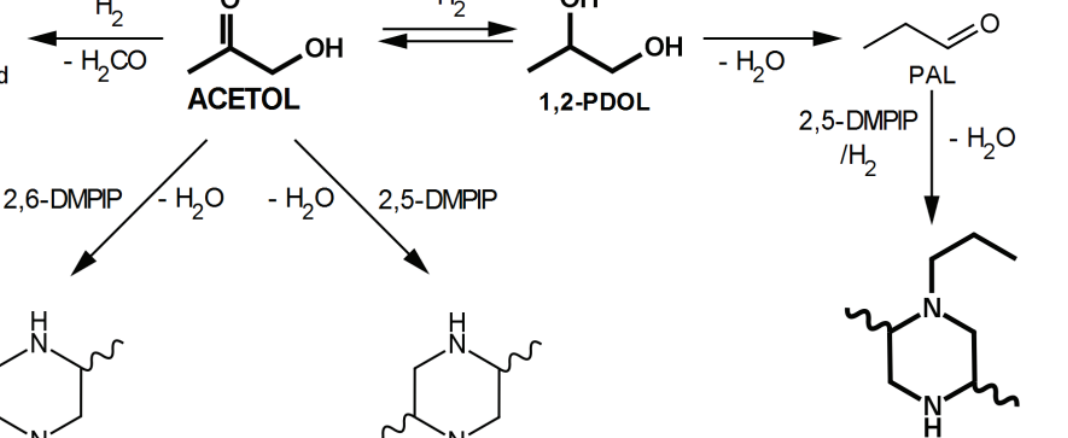

1-Ethyl-3,5-dimethylpiperazine<smiles>CC1CN(C(C)CO)CC(S)N1</smiles><smiles>CCC</smiles><smiles></smiles><smiles>OC=C1CCC1</smiles><smiles>C=C</smiles><smiles>[Tl]=C1CCCCC1</smiles>

2-(3,5-Dimethyl-1-piperazinyl)propanol<smiles>CC1CN(C(=O)C=O)CC(C)N1</smiles>

2-(2,3-Dimethyl-1-piperazinyl)-propionaldehyde
2,5-Dimethyl-1-propylpiperazine<smiles>CC(C)=CC#CC(C)N1CC(C)NCC1C</smiles><smiles>CC1CN(C(C)C=O)CC(C)N1</smiles><smiles>C=C=C</smiles>

2-(2,5-Dimethyl-1-piperazinyl)propanol -propionaldehyde

Scheme 8 - Proposed reaction pathways for the formation of identified (bold) N-substituted 2,5- and 2,6-DMPIP during the amination of acetol with ammonia in the presence of Ni-based catalyst 


\section{References}

1. Gomez, S., Peters, J. A., Maschmeyer, T., The reductive amination of aldehydes and ketones and the hydrogenation of nitriles: mechanistic aspects and selectivity control, Adv. Synth. Catal. 344 (2002) 1037.

doi: https://doi.org/10.1002/1615-4169(200212)344:10<10 37::AID-ADSC1037>3.0.CO; 2-3

2. Baiker, A., Caprez, W., Holstein, W. L., Catalytic amination of aliphatic alcohols in the gas and liquid phases: kinetics and reaction pathway, Ind. Eng. Chem. Prod. Res. Dev. 22 (1983) 217 doi: https://doi.org/10.1021/i300010a010

3. Baiker, A., Kijenski, J., Catalytic synthesis of higher aliphatic amines from the corresponding alcohols, Catal. Rev. Sci. Eng. 27 (1985) 653. doi: https://doi.org/10.1080/01614948508064235

4. Hayes, K. S., Industrial processes for manufacturing amines, Appl. Catal. A221 (2001) 187. doi: https://doi.org/10.1016/S0926-860X(01)00813-4

5. Eller, K., Henkes, E., Rossbacher, R., Höke, H., Amines, Aliphatic, Ullmann's Encyclopedia of Industrial Chemistry, 6th ed.; Wiley-VCh, 2000.

6. Frauenkron, M., Melder, J. P., Ruider, G., Rossbacher, R., Höke, H., Ethanolamines and Propanolamines, Ullmann's Encyclopedia of Industrial Chemistry, 6th ed., Wiley-VCh, 2001.

7. Fischer, A., Mallat, T., Baiker, A., Amination of diols and polyols to acyclic amines, Catal. Today 37 (1997) 167. doi: https://doi.org/10.1016/S0920-5861(97)00009-6

8. Boettger, G., Hoffman, H., Touissant, H., Winderl, S. (BASF) US Pat. Appl. 4,014,933, 29 Mar 1977; C.A. 76 (1977) 112663.

9. Cavitt, S. B., Speranza, G. P. (Jefferson Chemical Co., Inc.) US Pat. Appl. 3,448,153, 3 Jun 1969; C.A. 71 (1969) 49235.

10. Himmele, W., Hupfer, L., Toussaint, H., Paul, G. (BASF) DE Pat. Appl. 2,526,748, 14 Jun 1975; C.A. 86 (1977) 89182.

11. Cavitt, S. B., Speranza, G. P. (Jefferson Chemical Co., Inc.) US Pat. Appl. 3,448,153, 31 May 1966; C.A. 71 (1969) 49235.

12. Felder, E., Römer, M., Bardonner, H., Härtner, H., Fruhstorfer, W. (Merck) US Pat. Appl. 5,023,379, 12 Mar 1990; C.A.107 (1987) 238909.

13. Arredondo, V. M., Corrigan, P. J., Cearley, A. C., Back, D. J., Gibson, M. S., Fairweather, N. T. (The Procter \& Gamble Company) US Pat. Appl. 2007/0287868, 7 Jun 2007; C.A.148 (2007) 56952.

14. Arredondo, V. M., Corrigan, P. J. (The Procter \& Gamble Company) US Pat. Appl. 2007/0287865, 7 Jun 2007; C.A. 148 (2007) 56952.

15. Arredondo, V. M., Corrigan, P. J., Cearley, A. C., Fairweather, N. T., Gibson, M. S. (The Procter \& Gamble Company) US Pat. Appl. 2008/0045749, 7 Jun 2007; C.A. 148 (2007) 56952.

16. Arredondo, V. M., Corrigan, P. J., Cearley, A. C., Back, D. J., Gibson, M. S., Fairweather, N. T. (The Procter \& Gamble Company) US Pat. Appl. 7,619,119,13 Dec 2007; C.A. (2009) 56952

17. Gaines, J. R., Hansen, G. R. J., 3-Oxazolines, Heterocycl. Chem. 1 (1964) 96. doi: https://doi.org/10.1002/jhet.5570010209
18. Gaines, J. R., Lidel, D. D., Reactions of $\alpha$-hydroxy ketones with ammonia, J. Org. Chem. 28 (1963) 1032. doi: https://doi.org/10.1021/jo01039a039

19. Shu, Ch. K., Lawrence, B. M., Formation of 2-(1-hydroxyalkyl)-3-oxazolines from the reaction of acyloins and ammonia precursors under mild conditions, J. Agric. Food Chem. 43 (1995) 2922. doi: https://doi.org/10.1021/jf00059a028

20. Volf, J., Pašek, J., in: Červený, L. (Ed.), Studies in Surface Science and Catalysis, Elsevier, Amsterdam, 1986, pp. 105.

21. Jing, F., Zhang, Y., Luo, S., Chu, W., Zhang, H., Shi, X. J., Catalytic synthesis of 2-methylpyrazine over Cr-promoted copper based catalyst via a cyclo-dehydrogenation reaction route, Chem. Sci. 122 (2010) 621. doi: https://doi.org/10.1007/s12039-010-0097-5

22. Roundhill, D. M., Transition metal and enzyme catalyzed reactions involving reactions with ammonia and amines, Chem. Rev. 92 (1992) 1. doi: https://doi.org/10.1021/cr00009a001

23. Winans, C. F., Nickel as a catalyst for the hydrogenation of aromatic halogen compounds, J. Am. Chem. Soc. 61 (1939) 3566 . doi: https://doi.org/10.1021/ja01267a102

24. Winans, C. F. (Wingfoot Corp.) Pat. Appl. 2,217,630, Dec 1940, C.A. 35 (1940)6555.

25. Tlustý, T., Pašek, J., Voňka, P., Gas phase amination of octan-1-ol over a Cu-Cr catalyst, React. Kinet. Catal. Lett. 88 (2006) 371 . doi: https://doi.org/10.1007/s11144-006-0074-7

26. Fischer, A., Maciejewski, M., Bürgi, T., Mallat, T., Baiker, $A$., Cobalt-catalyzed amination of 1,3-propanediol: effects of catalyst promotion and use of supercritical ammonia as solvent and reactant, J. Catal. 183 (1999) 373. doi: https://doi.org/10.1006/jcat.1999.2408

27. Schwoegler, E. J., Adkins, H., Preparation of certain amines, J. Am. Chem. Soc. 61 (1939) 3499. doi: https://doi.org/10.1021/ja01267a081

28. Kort, M., Reactions of free sugars with aqueous ammonia, J. Adv. Carbohydr. Chem. 25 (1970) 311. doi: https://doi.org/10.1016/S0065-2318(08)60431-X

29. Nursten, H. E., The Maillard Reaction Chemistry: Biochemistry and Implications, The Royal Society of Chemistry, Cambridge, 2005, pp.1-89.

30. Ho, C. T., in: Ikan, R. (Ed.), The Maillard Reaction-Consequences for the Chemical and Life Sciences, John Wiley \& Sons Ltd, Chichester, 1996, pp. 27.

31. Shibamoto T., Akiyama T., Sakaguchi M., Enomoto Y., Masuda, H., A study of pyrazine formation, J. Agric. Food Chem. 27 (1979) 1027. doi: https://doi.org/10.1021/jf60225a051

32. Weenen $H$., Reactive intermediates and carbohydrate fragmentation in Maillard chemistry, Food Chem. 62 (1998) 393. doi: https://doi.org/10.1016/S0308-8146(98)00074-0

33. Rizzi, G. P., Mechanistic study of alkylpyrazine formation in model systems, J. Agric. Food Chem. 20 (1972) 1081. doi: https://doi.org/10.1021/jf60183a022

34. Yu, A. N., Tan, Z. W., Wang, F. S., Mechanistic studies on the formation of pyrazines by Maillard reaction between 1-ascorbic acid and 1-glutamic acid, LWT-Food Science and Technology 50 (2013) 64. doi: https://doi.org/10.1016/j.lwt.2012.07.001

35. Yaylayan, V. A., Majors, S. H., Ismail, A. A., Oxidation of diazinon by aqueous chlorine: kinetics, mechanisms, and product studies, J. Agric. Food Chem. 47 (1999) 2335. doi: https://doi.org/10.1021/jf9812836 
36. Amadori, M., Condensation between glucose and p-phenetidine, Atti. Accad. Lincei 2 (1925) 337.

37. Heyns, K., Paulsen, H., Breuer, H., Umsetzung von fructose mit aminosäuren zu glucosaminosäuren, Angew. Chem. 68 (1956) 334 doi: https://doi.org/10.1002/ange.19560680904

38. Heyns, K., Paulsen, H., Eichstedt, R., Rolle, M., Über die gewinnung von 2-aminoaldosen durch umlagerung von ketosylaminen, Chem. Ber. 90 (1957) 2039.

doi: https://doi.org/10.1002/cber.19570900949

39. Ahlbrecht, H., Zum problem der imin-enamin-tautomerie, Tetrahedron Lett. 9 (1968) 4421.

doi: https://doi.org/10.1016/S0040-4039(01)99149-X

40. Ahlbrecht, H., Blecher, J., Kröhnke, F., Zum problem der imin-enamin-tautomerie, Tetrahedron Lett. 10 (1969) 439. doi: https://doi.org/10.1016/S0040-4039(01)87713-3

41. Lin, J. F., Wu, Ch. Ch., Lien, M. H., Ab Initio study on the imine-enamine tautomerism of the alpha-substituted imines $\left(\mathrm{XH}_{2} \mathrm{CCH}: \mathrm{NH}, \mathrm{X}=\mathrm{H}, \mathrm{BH}_{2}, \mathrm{CH}_{3}, \mathrm{NH}_{2}, \mathrm{OH}, \mathrm{F}, \mathrm{Cl}, \mathrm{CN}\right.$, NO), J. Phys. Chem. 99 (1995) 16903. doi: https://doi.org/10.1021/j100046a015

42. Pérez, P., Toro-Labbé, A., Theoretical analysis of some substituted imine-enamine tautomerism, Theor. Chem. Acc. 105 (2001) 422.

doi: https://doi.org/10.1007/s002140000223

43. Arndt, F., Eistert, B., Über protonbeweglichkeit und ihre beeinflussung durch substituenten, insbesondere durch carbonyl- und sulfonylgruppen, Ber. Dtsch. Chem. Ges. 71 (1938) 2040.

doi: https://doi.org/10.1002/cber.19380711005

44. Bruckner, R., in: Harmata, M. (Ed.), Organic MechanismsReactions, Stereochemistry and Synthesis, Springer-Verlag, Berlin Heidelberg, 2010, pp.487-517.

45. Langdon, W. K., Levis, W. W. Jackson, D. R., Synthesis of pyrazines. Cycloamination of alkanolamines, Ind. Eng. Chem. Prod. Res. Develop. 1 (1962) 153. doi: https://doi.org/10.1021/i260002a016

46. Schubart, R., (Bayer A.G.) US Pat. Appl. 6,316,622, 15 Feb 2000; C.A. 133 (2000) 193172.

47. Baia, G., Chena, L., Lia, Y., Yana, X., Heb, F., Xinga, P., Zenga, T., Selective synthesis of cis-2,6-dimethylpiperazine catalyzed by a $\mathrm{Cu}-\mathrm{Cr}-\mathrm{Fe} / \gamma-\mathrm{Al} 2 \mathrm{O} 3$ catalyst, Appl. Catal. A277 (2004) 253

doi: https://doi.org/10.1016/j.apcata.2004.09.031

48. Guo, Y. F., Research of process synthesis of 2,5-dimethylpiperazine. M.S. Thesis, Nanjing University, China, June 2008

49. Feng, G. A., Preparation and separation process of 2,6-dimethylpiperazine. M.S. Thesis, Nanjing University, China, June 2009.

50. Yaylayan, V. A., Haffenden, L., Mechanism of imidazole and oxazole formation in [13C-2]-labelled glycine and alanine model systems, Food Chem. 81 (2003) 403. doi: https://doi.org/10.1016/S0308-8146(02)00470-3

51. Hwang, H. I., Hartman, T. G., Ho, C. T., Relative reactivities of amino acids in the formation of pyridines, pyrroles, and oxazoles, J. Agric. Food Chem. 43 (1995) 2917. doi: https://doi.org/10.1021/jf00059a027

52. Asinger, F., Thiel, M., Sowada, R., Synthesis and behavior of 3-imidazolines, Monatsh. Chem. 90 (1959) 402. doi: https://doi.org/10.1007/BF00901692

53. Yaylayan, V. A., Keyhani, A., Elucidation of the mechanism of pyrrole formation during thermal degradation of $13 \mathrm{C}$-labeled 1-serines, Food Chem. 74 (2001) 1. doi: https://doi.org/10.1016/S0308-8146(00)00332-0

54. von Braun, J., Blessing, G., Zobel, F., Katalytische hydrierungen unter druck bei gegenwart von nickelsalzen, VI.: Nitrile, Chem. Ber. 56 (1923) 1988. doi: https://doi.org/10.1002/cber.19230560845

55. Murahasi, S. I., Hirano, T., Yano, T., Palladium catalyzed amine exchange reaction of tertiary amines. Insertion of palladium(0) into carbon-hydrogen bonds, J. Am. Chem. Soc. 100 (1978) 348. doi: https://doi.org/10.1021/ja00469a093

56. Baiker, A., in: Guisnet, M., Barrault, J., Bouchoule, C., Duprez, D., Montassier, C.,. Pérot, G. (Eds.), Studies in Surface Science and Catalysis, Elsevier, Amsterdam, 1988, pp. 283.

57. Card, R. J., Schmitt, J. L., Gas-phase synthesis of nitriles, J. Org. Chem. 46 (1981) 754. doi: https://doi.org/10.1021/jo00317a020 